\title{
Examining the associations of autonomy and directive support given and received with relationship satisfaction in the context of goals that romantic partners have for one another
}

\author{
Noémie Carbonneau ${ }^{1}\left[\right.$ ] Tamas Martos $^{2} \cdot$ Viola Sallay $^{2} \cdot$ Samuel Rochette $^{1} \cdot$ Richard Koestner $^{3}$
}

(c) Springer Science+Business Media, LLC, part of Springer Nature 2019

\begin{abstract}
Previous research has shown unique benefits associated with both providing and receiving autonomy-support among samesex friends (Deci et al. 2006). The present research examined the provision and receipt of two types of goal support from the viewpoints of the two partners in heterosexual couples $(n=247$ Hungarian couples). The level of autonomy and directive support that each partner delivered and received in relation to vicarious goals (i.e., goals that partners have for one another) was assessed. Autonomy support from the partner was found to be consistently and positively associated with relationship satisfaction, and this pattern of results was found whether we considered perceived autonomy support from the partner or actual partner report of support given. In addition, providing autonomy support to one's partner was found to positively relate to relationship satisfaction over and above the effects of receiving support. Overall, directive support was found to be either unrelated or negatively related to relationship satisfaction, suggesting that it can actually backfire and impair satisfaction. Overall, results underscore the relational benefits of supporting vicarious goals in an autonomous rather than directive manner. These findings have implications regarding the pursuit of goals in the context of romantic relationships.
\end{abstract}

Keywords Goal support · Vicarious goals · Autonomy support · Directive support · Relationship satisfaction · Romantic relationships

Being a part of dyads and social groups provides individuals with greater access to social support, which can help individuals cope with adverse situations (Cohen and McKay 1984) and achieve desired personal goals (Duncan et al. 2005). Not all forms of support are equally beneficial, however, with recent research indicating that autonomous support of goal pursuits (providing support with empathy such that the other feels understood and cared for) is related to more positive outcomes for the recipient than support that is more directive (e.g., Koestner et al. 2012; Koestner et al. 2015). Furthermore, although the benefits of receiving support from others have been well documented (e.g., Cheng and Boey 2000; Helgeson and Cohen 1996; Uchino et al.

Noémie Carbonneau

noemie.carbonneau@uqtr.ca

1 Université du Québec à Trois-Rivières, Trois-Rivières, Canada

2 University of Szeged, Szeged, Hungary

3 McGill University, Montreal, Canada
1996), research has also demonstrated important positive outcomes associated with providing support to others (e.g., Inagaki and Orehek 2017). Indeed, research by Deci et al. (2006) suggests that there are unique benefits associated with both providing and receiving autonomy-support among same-sex friends. Focusing on vicarious goals (i.e., goals that partners have for one another) in the context of romantic relationships, the present research aims to examine whether providing autonomy and directive support contribute to the prediction of relationship satisfaction over and above the effects of receiving goal support. We also examine whether the associations between goal support and relationship satisfaction depend on whose perspective (i.e., the provider or recipient of support) is considered.

\section{On autonomy-support and directive support}

In recent research, Koestner et al. have distinguished two forms of goal support from close others: autonomy and directive support (Koestner et al. 2012, 2015; Powers et al. 
2008). Autonomy support encompasses interpersonal behaviors such as providing choice and options to a relationship partner (e.g., child, friend, spouse), nurturing his/her inner motivational resources, acknowledging his/her feelings, and empathizing with his/her perspectives (e.g., Deci and Ryan 2000; Reeve 2009; Ryan and Deci 2000). In contrast, directive support is characterized by providing guidance, advice, and reminders, and emphasizing the actions that the other person should take in order to reach a given goal (Chua et al. 2015; Koestner et al. 2012; Koestner et al. 2015). Relationships characterized by autonomy (vs. directive) support allow greater opportunities for self-initiation and choice, and should therefore be associated with greater personal and relational benefits (Koestner et al. 2012). This is consistent with research showing that autonomy support is largely related to positive outcomes (Ryan and Deci 2017). However, the picture is not as clear for directive support (Gorin et al. 2014; Koestner et al. 2012; Koestner et al. 2015; Powers et al. 2008). For example, autonomy-support has been shown to be positively related to goal progress, psychological well-being, and relationship quality, whereas directive support was only marginally related to better goal progress but unrelated to either relationship quality or psychological well-being (Koestner et al. 2012). More recent research suggests that directive support is sometimes associated with negative outcomes (Gorin et al. 2014; Koestner et al. 2015). More specifically, Koestner et al. (2015) contend that directive support has negative effects on important developmental goals because it negatively predicts both goal internalization and goal satisfaction. In addition, research by Gorin et al. (2014) found that autonomy support from one's partner facilitates weight loss while some forms of directive support are associated with less weight loss. Other research suggests that in the context of certain relationships that highlight issues of autonomy-such as parent's support of young adults career goals - there is emerging evidence that directive support can actually backfire resulting in retarded goal progress (Koestner et al. 2016).

In the present study, autonomy and directive support between romantic partners are examined in relation to relationship satisfaction. Overall, we expect autonomy support to be a better predictor of relationship satisfaction than directive support, a prediction that is in line with the tenets of Self-Determination Theory (e.g., Deci and Ryan 2000; Ryan and Deci 2000). This theory posits the existence of three basic psychological needs (i.e., for autonomy, competence, and relatedness), that are essential nutriments that promote personal growth, thriving, and well-being (Ryan and Deci 2000). Satisfaction of these needs has been related to numerous positive outcomes including psychological and physical well-being (Deci and Ryan 2000). Important links have also been documented between need satisfaction and dyadic functioning. For example, individuals report more relational well-being in close relationships where they experience greater satisfaction of their psychological needs $(\mathrm{La}$ Guardia et al. 2000). Deci and Ryan (2014) further argue that for close relationships to be experienced as being of high quality, the two partners need to experience autonomy and give each other autonomy support. In contrast, relationships in which the partners' need for autonomy is not fully satisfied should result in less positive feelings about the relationship. In the present research, we expect autonomy support with regard to vicarious goals to promote more positive feelings about the relationship than directive support-a prediction consistent with Self-Determination Theory and past research.

\section{On the benefits of giving support}

There is growing evidence that providing support to others produces emotional, physical, and social benefits (Inagaki and Orehek 2017). For example, in a sample of young adults, Piferi and Lawler (2006) found that giving social support was associated with reduced cardiovascular activity (i.e., lower blood pressure and heart rate) independently of receiving support. Research conducted in laboratory settings also suggests that providing support has stress-reducing effects (Inagaki and Eisenberger 2012). Among older adults, giving and receiving support independently contributed to the positive health status (Momtaz et al. 2014). Further, in a study of recovery from the loss of a spouse, helping behaviors toward others performed by bereaved individuals predicted an accelerated decline in depression, independent of support received (Brown et al. 2008). In another study, researchers demonstrated that giving emotional support to one's romantic partner uniquely predicted a reduced risk of mortality over 5 years for the provider, beyond the effects of receiving support (Brown et al. 2003). Interestingly, Brown et al. (2003) argued that in some contexts, providing support might be more beneficial than receiving support.

\section{Support in dyadic relationships: On taking both members of the dyad into account}

Even though social support is transactional in nature (Kahn and Antonuci 1980), studies examining support in dyadic relationships often analyze the perspective of only one member of the dyad. When conducting research on individuals rather than dyads, researchers usually target either the provider or recipient of support. Research into autonomy-support has mainly focused on the point of view of the recipient of support. For example, participants have been asked to report their perceptions of autonomy support provided to them by various types of relationship partners such as 
their supervisor (e.g., Gillet et al. 2012), teacher (e.g., Guay et al. 2001), coach (e.g., Pelletier et al. 2001), parent (e.g., Brenning et al. 2015), romantic partner (e.g., Carbonneau et al. 2015), or best friend (e.g., Demir et al. 2011). Only a few studies focused on the point of view of the provider of autonomy support: for example, Solstad et al. (2015) examined the degree to which coaches reported supporting the autonomy of their athletes, and Mageau et al. (2017) examined the degree to which mothers reported being supportive of their children's autonomy.

One of the few studies in which autonomy support has been examined from the point of view of both dyad members is that of Hanna et al. (2013). These researchers examined autonomy support in parent-adolescent dyads and assessed autonomy-support from the standpoints of both the providers of support (i.e., parents) and the recipients of support (i.e., adolescents). They found a moderate correlation $(r=.46)$ between parents' and adolescents' reports of parental autonomy-support. Deci et al. (2006) conducted a series of studies on the benefits of providing and receiving autonomy support in close, same-sex, friendships. Small to moderate correlations were found between autonomy support received and given by a person and between friends' perceptions of the autonomy support they receive and provide in the relationship. These results point to mutuality of autonomy support in close friendships. In addition, participants' reports of the autonomy support they receive and provide from/to their friend were both found to positively predict their own relationship quality. Directive support was not assessed in these studies.

\section{On the importance of examining support in the context of vicarious goals}

While personal goals have been largely studied, especially from the Self-Determination Theory perspective, vicarious goals are a distinct type of goals also worth examining. These are defined as goals that are adopted and pursued because of other people in one's life (Carbonneau and Milyavskaya 2017; Koestner et al. 2012, Study 3). Given that these goals have been generated by someone else, they risk being experienced as more controlled than self-initiated goals. Given the social context in which vicarious goals are embedded, the type of support (autonomy supportive or directive) of the person who prompted the goal could play an important role in determining whether these goals affect one's relationship with the goal generator in a positive or negative way.

Research by Mageau et al. (2016) showed that vicarious goals are common in parent-child relationships. More specifically, they examined achievement goals that parents have for their children. They found that parental achievement goals, just like personal achievement goals, can be mastery, performance-approach or performanceavoidance oriented. More importantly, they found that types of goals predict mothers' tendency to adopt autonomy-supportive and controlling behaviors: mothers who have performance goals for their teenager are more controlling while parents with mastery goals for their teenager display more autonomy-supportive behaviors.

Although vicarious goals are likely to be at play in hierarchical relationships (such as parent-child relationships), they can also manifest in more egalitarian relationships such as friendships and romantic partnerships (e.g., Carbonneau and Milyavskaya 2017; Koestner et al. 2012, Study 3). Research by Markey et al. (2008) suggest that vicarious goals are rather common between romantic partners, at least in the sphere of eating where partners often attempt to regulate one another's eating behaviors. Building on research by Markey et al. (2008), Carbonneau and Milyavskaya (2017) showed that vicarious goals individuals have for their romantic partner are likely to originate from goals that they themselves pursue. Results of this research show that whether women want their partner to regulate their eating behaviors mainly for appearance or health reasons depends on their own personal reasons for pursuing such goals. More importantly, this research shows that when women's vicarious eating regulation goals for their male partner are accompanied with an empathic, autonomy-supportive attitude, men report higher psychological well-being. Conversely, men whose female partner rely on a controlling attitude when trying to motivate them to regulate their eating behaviors report both lower psychological well-being and relationship satisfaction. Further attesting to the benefits of autonomysupport in relation to vicarious goals are the results of Koestner et al. (2012, Study 3), showing that perceived autonomy support from the goal provider is related to greater psychological well-being, relationship quality, and progress toward the vicarious goal, whereas directive support is not significantly related to these outcomes.

Given that vicarious goals are common between romantic partners and that the romantic relationship is central in many people's lives, it would thus appear important to conduct further research on how autonomy and directive support function in relation to vicarious goals' impact on couples' relationship functioning. Research has shown that perceived autonomy support is related to greater relationship quality with the goal provider than perceived directive support (Koestner et al. 2012, Study 3), but does actual partner report of support given relates to one's satisfaction with the relationship? And does one's provision of support to the partner contribute to one's relationship satisfaction over and above the benefits of receiving support? These are some of the questions that the present research sought to explore. 


\section{The present research}

Our general aim was to examine provision and receipt of autonomy and directive support from the viewpoints of the two partners in heterosexual couples. Two hundred and forty seven Hungarian couples were recruited for a study that focused on vicarious goals. In this study, vicarious goals refer to goals that relationship partners have for one another (Carbonneau and Milyavskaya 2017; Koestner et al. 2012). Examples include: "I would like my partner to continue her studies" and "I want my partner to take better care of his health." How support impacts the relationship appears especially important to examine in relation to vicarious goals given that individuals should be particularly motivated to ensure that their partner pursue and attain such goals. In the present study, we assessed the level of autonomy and directive support that each partner delivered and received in relation to the vicarious goals they had for one another.

In line with past research, three main predictions were derived. Previous studies showed that perceived autonomy support was better than directive support in terms of leading to goal progress and relationship satisfaction (Koestner et al. 2012; Study 3). The current study will distinguish perceived and objective levels of support given by the partner. This will allow us to test whether actual reports of partner giving autonomy and directive support relate to one's own satisfaction. Our first prediction is that the positive association between receiving support and relationship satisfaction would be observed regardless of whether we consider perceived or objective support.

In this research, we also examined whether providing support to one's partner would relate to one's own relationship satisfaction over and above the effect of receiving support. Our second prediction is that giving autonomy support to one's partner would enhance relationship satisfaction independently from receiving support. Giving directive support to one's partner was not expected to enhance relationship satisfaction. It was further expected that this pattern of results would be found whether we considered support given from the point of view of the provider or the recipient of support.

Finally, in line with past research (e.g., Gorin et al. 2014; Koestner et al. 2015), our third prediction is that directive support can sometimes backfire and actually impair relationship functioning. Overall, directive support was thus expected to be either unrelated or negatively related to relationship satisfaction.

\section{Method}

\section{Participants and procedure}

Participants were 247 heterosexual couples from Hungary. Mean age was 39.97 years for men $(\mathrm{SD}=10.71$ years) and
37.74 years for women $(\mathrm{SD}=10.08$ years). The average relationship length was 13.42 years ( $\mathrm{SD}=9.53$ years). Regarding relationship status, 106 couples $(42.9 \%)$ were cohabiting, and 136 were married (55.1\%); relationship status was missing for five couples (2\%).

Participants were recruited in the central region of Hungary by a market research firm that chose potential participants from its pool of former participants and contacted them through experienced interviewers. Inclusion criteria were: at least 1 year of cohabitation, at least one partner has a job, no psychiatric event in the last 5 years. Those who participated in the procedure received a gift certificate for their contribution $(6000$ HUF, US $\$ 20$ per couple). All procedures were completed in the homes of participants. Institutional Review Board (IRB) approval was obtained at the Semmelweis University, Budapest. Participants gave informed consent prior to their participation in the study.

\section{Instruments}

\section{Demographic variables}

Participants completed a demographic information section that included questions on gender, age, relationship status and relationship length among others.

\section{Identification of a vicarious goal}

Couple members were asked to think of a goal each of them has for the other and that he/she is pursuing. Examples include "I want my partner to exercise more" and "I want him to pay off all his debts." Support that participants provided to their partners in relation to the goal they have for them was first assessed. Subsequently, participants wrote their vicarious goal on a sheet and the interviewer handed it to the partner. Participants then reported the support they received in relation to the goal their partner has for them. Partners did not communicate during the session.

\section{Support received from the partner}

Participants were asked to rate the support they receive from their partner using Koestner et al.'s (2012) goal support scale. This scale includes six items assessing autonomy support (e.g., "I feel that my partner understands how I see things with respect to this goal") and seven items assessing directive support (e.g., "My partner repeatedly reminds me of this goal"). Responses were scored on a 
seven-point Likert-type scale ranging from 1 (not at all true) to 7 (very true). In the present study, the Cronbach's alpha was .88 for autonomy support and .85 for directive support.

\section{Support provided to the partner}

The same scale (Koestner et al. 2012) was used to assess the support participants provide to their partner. Examples of items include "I show my partner that I understand how he/ she sees things with respect to this goal" (autonomy support) and "I repeatedly remind my partner of this goal" (directive support). Responses were scored on a seven-point Likert scale ranging from 1 (not at all true) to 7 (very true). In the present study, the Cronbach's alpha was .86 for autonomy support and .83 for directive support.

\section{Relationship satisfaction}

The seven-item Relationship Assessment Scale (RAS; Hendrick 1988) was used to assess relationship satisfaction. A sample item is: "In general, how satisfied are you with your relationship?" Responses were scored on a five-point Likert scale ranging from 1 (unsatisfied/poor/never, etc.) to 5 (extremely satisfied/excellent/very often, etc.). In the present study, the Cronbach's alpha was .87.

\section{Results and discussion}

Means, standard deviations, and correlations of the study variables appear in Table 1. It can be seen that the goal support tended to be more autonomous rather than directive. We first conducted correlational analyses in order to examine potential associations between the study variables and demographics. Participants' age was not significantly related to autonomy and directive support given or receive, nor to relationship satisfaction ( $r$ s ranging from -.083 to .032 ; $p$ s ranging from .072 to .353). Relationship length showed only modest associations with autonomy support given $(r=-.112, p<.05)$ and relationship satisfaction $(r=-.097$, $p<.05)$. ANOVAs were also conducted and revealed that the levels of some of the study variables significantly differed according to gender and marital status. More specifically, women reported providing more directive support to their partner than men $(M=4.83$ vs. $4.47 ; F[1,493]=10.28$, $p<.05)$. In addition, individuals in cohabiting couples reported providing more autonomy support ( $M=6.20$ vs. 5.97; $F[1,483]=7.91, p<.05)$ and also more directive support $(M=4.91$ vs. $4.45 ; F[1,483]=15.21, p<.05)$ to their partner than individuals in married couple. Gender and marital status were therefore controlled for in the regression analyses.

\section{Examining the associations of perceived and objective levels of support given by the partner with relationship satisfaction}

A first regression analysis was conducted to examine whether perceived levels of support given by the partner were related to one's relationship satisfaction. Controlling for gender and marital status, perceived autonomy support from the partner was significantly and positively related to one's relationship satisfaction $(\beta=.390, p<.05)$ whereas perceived partner directive support was negatively related to it $(\beta=-.114, p<.05)$. A second regression analysis was conducted to examine whether actual levels of support given by the partner were related to one's satisfaction with the relationship. Actual levels of autonomy $(\beta=.266, p<.05)$ and directive $(\beta=-.113, p<.05)$ support from the partner were respectively positively and negatively related to one's relationship satisfaction.

\section{Examining whether providing support to one's partner enhances one's relationship satisfaction independently from receiving support}

Hierarchical regression analyses were conducted in order to examine whether providing support to one's partner would relate to one's relationship satisfaction over and above the effect of receiving support. Relationship satisfaction was hierarchically regressed on gender and marital status (Step
Table 1 Means, standard deviations, and correlations of the study variables

\begin{tabular}{lrrrrrrrr}
\hline & Mean & $\begin{array}{c}\text { Standard } \\
\text { deviation }\end{array}$ & 1 & 2 & 3 & 4 & 5 \\
\hline 1. Autonomy support given to the partner & 6.065 & .913 & 1 & $.117^{*}$ & $.507^{*}$ & $.136^{*}$ & $.303^{*}$ \\
2. Directive support given to the partner & 4.650 & 1.284 & & & 1 & .071 & $.504^{*}$ & $-.137^{*}$ \\
3. Autonomy support received from partner & 5.965 & .987 & & & 1 & .060 & $.383^{*}$ \\
4. Directive support received from partner & 4.592 & 1.371 & & & & 1 & -.059 \\
5. Relationship satisfaction & 4.345 & .609 & & & & & 1 \\
\hline
\end{tabular}

All scales range from 1 to 7 except for the relationship satisfaction scale, that ranges from 1 to $5 ; n=494$

$* p<.05$ 
1), autonomy and directive support received (Step 2), and autonomy and directive support given (Step 3). As can be seen in Table 2, support received made an important contribution to the prediction of relationship satisfaction $(15.8 \%$ of the variance). Nevertheless, adding the provision of autonomy and directive support to one's partner to the regression had a significant incremental predictive value $\left(\Delta R^{2}\right.$ of $3.5 \%, p<.05)$ with respect to one's relationship satisfaction. More specifically, providing autonomy and directive support to one's partner were respectively found to positively $(\beta=.165, p<.05)$ and negatively $(\beta=-.152, p<.05)$ predict one's relationship satisfaction over and above the effect of receiving support. Similar patterns of results were obtained when the hierarchical regression was conducted using one's provision of support to the partner as reported by the partner him/herself (i.e., the recipient of support). More specifically, autonomy support given positively predicted one's relationship satisfaction $(\beta=.206, p<.05)$ whereas directive support negatively predicted this outcome positively $(\beta=-.059$, $p=.168)$, although this relationship did not reach statistical significance.

\section{Discussion}

The general purpose of this research was to examine how the provision and receipt of autonomous and directive goal support relate to satisfaction in the context of romantic relationships. Support was examined in relation to vicarious goals, or goals that partners have for one another. In line with past research (Gorin et al. 2014; Koestner et al. 2012, 2015; Powers et al. 2008), we made three predictions with regard to the associations between support for vicarious goal and relationship satisfaction. First, we expected that autonomy support by the partner would be better than directive support in terms of leading to relationship satisfaction. This pattern of results was expected to be observed whether we consider individuals' perceptions of partner support or actual reports of partner giving support. This prediction was fully supported by our results. Second, we expected that the provision of autonomy support to one's partner would predict one's own relationship satisfaction over and above the beneficial effect of receiving support from the partner. Taking advantage of the two sources of data, we were able to examine this pattern of associations from the point of view of both the support provider and recipient. More specifically, results showed that providing autonomy support to the partner predicted one's increased relationship quality. In addition, we found that the partner reports of one's provision of autonomy support was also associated with one's feeling higher satisfaction in the relationship. Finally, in line with past research (e.g., Gorin et al. 2014; Koestner et al. 2015), our third prediction was that directive support can backfire and actually hinder relationship functioning. Our results show that perceiving and giving directive support can sometimes impair relationship satisfaction. The negative results for directive support is in line with recent indications that directive support may backfire for certain types of goals and for certain kinds of relationships. In this case, it seems that having a partner who is constantly emphasizing the actions one should take in order to reach some goal is likely to erode one's satisfaction with the relationship. Interestingly, individuals who find themselves frequently reminding their partner about why they need to pursue a given goal
Table 2 Hierarchical Regression Analyses of Support Received and Given on Relationship Satisfaction

\begin{tabular}{|c|c|c|c|c|c|c|}
\hline & $R$ & $R^{2}$ & $\Delta R^{2}$ & $\beta$ & $t$ & $p$ \\
\hline Step 1 & .042 & .002 & & & & \\
\hline Gender & & & & -.042 & -.913 & .362 \\
\hline Marital status & & & & .009 & .187 & .852 \\
\hline Step 2 & 400 & .160 & $.158(p<.05)$ & & & \\
\hline Autonomy support received & & & & .394 & 9.364 & $<.05$ \\
\hline Directive support received & & & & -.089 & -2.117 & $<.05$ \\
\hline \multicolumn{7}{|c|}{ Step 3 (when support given is reported by the provider) } \\
\hline & .442 & .195 & $.035(p<.05)$ & & & \\
\hline Autonomy support given & & & & .165 & 3.431 & $<.05$ \\
\hline Directive support given & & & & -.152 & -3.091 & $<.05$ \\
\hline \multicolumn{7}{|c|}{ Step 3 (when support given is reported by the recipient) } \\
\hline & .445 & .198 & $.027(p<.05)$ & & & \\
\hline Autonomy support given & & & & .206 & 4.614 & $<.05$ \\
\hline Directive support given & & & & -.059 & -1.382 & .168 \\
\hline
\end{tabular}

The three steps represent the order of entry for the variables. Marital status is coded " 1 " for the married couples and " 2 " for the cohabiting couples; $n=494$ 
and how to do it are also likely to experience diminished relationship satisfaction.

Research on the relative visibility of support (Bolger et al. 2000; Girme et al. 2013) offers plausible explanations for the negative associations between directive support and relationship satisfaction. In line with Bolger et al.'s (2000) work, we believe that directive support represents a more visible form of support than autonomy support. Past research has shown that visible support may have adverse effects on recipients' self-image. This kind of support may thus be interpreted by recipients as their partner's lack of trust in their ability to reach a goal, which can reduce their goal-related confidence and feelings of efficacy (Girme et al. 2013; Overall et al. 2016).

The null or negative effects of directive goal support are also consistent with research on dependency-oriented support (i.e., helping to solve the problem) versus autonomyoriented support (i.e., providing tool with which to solve the problem) (e.g., Hammond and Overall 2015; Nadler 1998, 2002, 2015; Nadler and Chernyak-Hai 2014). When individuals are told by their partner how to pursue a goal (i.e., dependency-oriented support), they may feel that their partner underestimates their knowledge and skills (e.g., Hammond and Overall 2015), which may reduce their satisfaction with the relationship. Results of the present study suggest that this may be especially true in romantic relationships. Regarding the negative association between provision of directive support and relationship satisfaction, it might be that finding oneself in a position of constantly monitoring their partner's behavior to make sure that they pursue a certain goal would make individuals question whether they really share similar life goals with their partner after all.

Future research should examine personal and relational characteristics that predict whether one is more likely to provide autonomy versus directive support to one's romantic partner. For example, individuals who report higher inclusion of their partner in the self (e.g., Aron et al. 1992; Aron et al. 1991) might be particularly motivated to support their partner's goal pursuit given that their partner's accomplishments are perceived, to some extent, as their own. We posit that a high degree of inclusion of other combined with an anxious personality should lead to a more directive attitude in relation to the partner's goal pursuit. In contrast, if combined with an empathic personality, inclusion of the partner in the self should foster autonomy support between the partners.

While goal support has been mostly studied in relation to personal goals, our focus in this research was on vicarious goals. More specifically, we examined autonomy/directive support in relation to a goal that individuals have for their romantic partner and that he/she is pursuing. A question of interest here is: what happens when a person's vicarious goal for his/her partner is oriented toward a behavior (e.g., to exercise more) or outcome (e.g., to acquire a lot of money) that is not relevant to the partner's ideal self (Rusbult et al. 2005)? Are people more likely to be directive if they feel that their partner does not endorse a given goal to the same level as they personally do? For example, we posit that a wife who wants her husband to eat better and who is also pursuing this goal will be more likely to offer directive versus autonomy support to her husband if she feels that he is not invested in this goal as much as she is. These hypotheses should be tested in future research.

Overall, three findings stand out in our present research. First, the giving of autonomy support had a consistent positive effect on relationship satisfaction that was independent of the effects of receiving support. Importantly, the present study showed the benefits of giving support in the context of growth-oriented goal support rather than in the typical context of helping a partner cope with a distressing situation (Feeney and Collins 2015). Second, the overall pattern of associations between autonomy/directive support and relationship satisfaction was found whether we considered support from the point of view of the provider or recipient of support. Third, the present research confirmed the particular relational benefits of supporting goals in an autonomous rather than directive manner. Given the evidence that teachers and coaches can be taught to provide more autonomy supportive feedback, future research should explore whether individuals can learn to highlight autonomous rather than directive support in relation to the goals they have for their romantic partner.

Funding This study was funded by the Hungarian Scientific Research Fund (OTKA; Grant No. PD 105685) and by the Fonds de Recherche du Québec-Société et Culture (FRQSC; Grant No. 179720).

\section{Compliance with ethical standards}

Conflict of interest None of the authors has any conflict of interest.

Ethical approval All procedures were in accordance with the ethical standards of the institutional and/or national research committee and with the 1964 Helsinki declaration and its later amendments or comparable ethical standards.

Informed consent Informed consent was obtained from all individual participants included in the study.

\section{References}

Aron, A., Aron, E. N., \& Smollan, D. (1992). Inclusion of other in the self scale and the structure of interpersonal closeness. Journal of Personality and Social Psychology, 63, 596-612. 
Aron, A., Aron, E. N., Tudor, M., \& Nelson, G. (1991). Close relationships as including other in the self. Journal of Personality and Social Psychology, 60, 241-253.

Bolger, N., Zuckerman, A., \& Kessler, R. C. (2000). Invisible support and adjustment to stress. Journal of Personality and Social Psychology, 79, 953-961.

Brenning, K., Soenens, B., Van Petegem, S., \& Vansteenkiste, M. (2015). Perceived maternal autonomy support and early adolescent emotion regulation: A longitudinal study. Social Development, 24, 561-578.

Brown, S. L., Brown, R. M., House, J. S., \& Smith, D. M. (2008). Coping with spousal loss: Potential buffering effects of self-reported helping behavior. Personality and Social Psychology Bulletin, 34, 849-861.

Brown, S. L., Nesse, R. M., Vinokur, A. D., \& Smith, D. M. (2003). Providing social support may be more beneficial than receiving it: Results from a prospective study of mortality. Psychological Science, 14, 320-327.

Carbonneau, N., Carbonneau, E., Cantin, M., \& Gagnon-Girouard, M.-P. (2015). Examining women's perceptions of their mother's and romantic partner's interpersonal styles for a better understanding of their eating regulation and intuitive eating. Appetite, 92, $156-166$

Carbonneau, N., \& Milyavskaya, M. (2017). Your goals or mine? Women's personal and vicarious eating regulation goals and their partners' perceptions of support, well-being, and relationship quality. Motivation and Emotion, 41, 465-477.

Cheng, T. Y. L., \& Boey, K. W. (2000). Coping, social support, and depressive symptoms of older adults with type II diabetes mellitus. Clinical Gerontologist: The Journal of Aging and Mental Health, 22, 15-30.

Chua, S., Carbonneau, N., Milyavskaya, M., \& Koestner, R. (2015). Beyond the self in self-control: The role of relational interdependent self-construal in goal pursuit. Journal of Social and Personal Relationships, 32, 330-343.

Cohen, S., \& McKay, G. (1984). Social support, stress and the buffering hypothesis: A theoretical analysis. In A. Baum, S. E. Taylor, \& J. E. Singer (Eds.), Handbook of psychology and health (pp. 253-267). Hillsdale, NJ: Erlbaum.

Deci, E. L., La Guardia, J. G., Moller, A. C., Scheiner, M. J., \& Ryan, R. M. (2006). On the benefits of giving as well as receiving autonomy support: Mutuality in close friendships. Personality and Social Psychology Bulletin, 32, 313-327.

Deci, E. L., \& Ryan, R. M. (2000). The "what" and "why" of goal pursuits: Human needs and the self-determination of behavior. Psychological Inquiry, 11, 227-268.

Deci, E. L., \& Ryan, R. M. (2014). Autonomy and need satisfaction in close relationships: Relationships motivation theory. In N. Weinstein (Ed.), Human motivation and interpersonal relationships: Theory, research, and applications (pp. 53-73). Dordrecht, Netherlands: Springer.

Demir, M., Özdemir, M., \& Marum, K. P. (2011). Perceived autonomy support, friendship maintenance, and happiness. The Journal of Psychology, 145, 537-571.

Duncan, S. C., Duncan, T. E., \& Strycker, L. A. (2005). Sources and types of social support in youth physical activity. Health Psychology, 24, 3-10.

Feeney, B. C., \& Collins, N. L. (2015). A new look at social support: A theoretical perspective on thriving through relationships. Personality and Social Psychology Review, 19, 113-147.

Gillet, N., Fouquereau, E., Forest, J., Brunault, P., \& Colombat, P. (2012). The impact of organizational factors on psychological needs and their relations with well-being. Journal of Business and Psychology, 27, 437-450.
Girme, Y. U., Overall, N. C., \& Simpson, J. A. (2013). When visibility matters: Short-term versus long-term costs and benefits of visible and invisible support. Personality and Social Psychology Bulletin, $39,1441-1454$.

Gorin, A. A., Powers, T. A., Koestner, R., Wing, R., \& Raynor, H. (2014). Autonomy support, self-regulation, and weight loss. Health Psychology, 33, 332-339.

Guay, F., Boggiano, A. K., \& Vallerand, R. J. (2001). Autonomy support, intrinsic motivation, and perceived competence: Conceptual and empirical linkages. Personality and Social Psychology Bulletin, 27, 643-650.

Hammond, M. D., \& Overall, N. C. (2015). Benevolent sexism and support of romantic partner's goals: Undermining women's competence while fulfilling men's intimacy needs. Personality and Social Psychology Bulletin, 41, 1180-1194.

Hanna, K. M., Dashiff, C. J., Stump, T. E., \& Weaver, M. T. (2013). Parent-adolescent dyads: Association of parental autonomy support and parent-adolescent shared diabetes care responsibility. Child: Care, Health and Development, 39, 695-702.

Helgeson, V. S., \& Cohen, S. (1996). Social support and adjustement to cancer: Reconcilling descriptive, correlational, and intervention research. Health Psychology, 15, 135-148.

Hendrick, S. S. (1988). A generic measure of relationship satisfaction. Journal of Marriage and the Family, 50(1), 93-98.

Inagaki, T. K., \& Eisenberger, N. I. (2012). Neural correlates of giving support to a loved one. Psychosomatic Medicine, 74, 3-7.

Inagaki, T. K., \& Orehek, E. (2017). On the benefits of giving social support: When, why, and how support providers gain by caring for others. Current Directions in Psychological Science, 26, 109-113.

Kahn, R. L., \& Antonuci, T. C. (1980). Convoys over the life course: Attachment, roles and social support. In P. B. Baltes \& O. G. Brim (Eds.), Life-span development and behavior (pp. 253-286). New York: Academic Press.

Koestner, R., Powers, T. A., Carbonneau, N., Milyavskaya, M., \& Chua, S. N. (2012). Distinguishing autonomous and directive forms of goal support: Their effects on goal progress, relationship quality, and subjective well-being. Personality and Social Psychology Bulletin, 38, 1609-1620.

Koestner, R., Powers, T., Holding, A., Hope, N., \& Milyavskaya, M. (2016). Parents autonomous and directive support of their young adult children's goals. Toronto, CA: American Psychological Association.

Koestner, R., Powers, T. A., Milyavskaya, M., Carbonneau, N., \& Hope, N. (2015). Goal internalization and persistence as a function of autonomous and directive forms of goal support. Journal of Personality, 83, 179-190.

La Guardia, J. G., Ryan, R. M., Couchman, C. E., \& Deci, E. L. (2000). Within-person variation in security of attachment: A self-determination theory perspective on attachment, need fulfillment, and well-being. Journal of Personality and Social Psychology, 79, 367-384.

Mageau, G. A., Bureau, J. S., Ranger, F., Allen, M.-P., \& Soenens, B. (2016). Parental achievement goals as determinants of autonomysupportive and controlling parenting. Journal of Child and Family Studies, 25, 1702-1711.

Mageau, G. A., Sherman, A., Grusec, J. E., Koestner, R., \& Bureau, J. S. (2017). Different ways of knowing a child and their relations to mother-reported autonomy support. Social Development, 26, 630-644. https://doi.org/10.1111/sode.12212.

Markey, C. N., Gomel, J. N., \& Markey, P. M. (2008). Romantic relationships and eating regulation: an investigation of partners' attempts to control each others' eating behaviors. Journal of Health Psychology, 13, 422-432. 
Momtaz, Y. A., Ibrahim, R., \& Hamid, T. A. (2014). The impact of giving support to others on older adults' perceived health status. Psychogeriatrics, 14, 31-37.

Nadler, A. (1998). Relationship, esteem, and achievement perspectives on autonomous and dependent help-seeking. In S. A. Karabenick (Ed.), Strategic help seeking: Implications for learning and teaching (pp. 61-95). Mahwah, NJ: Lawrence Erlbaum.

Nadler, A. (2002). Inter-group helping relations as power relations: Maintaining or challenging social dominance between groups through helping. Journal of Social Issues, 58, 487-502. https:// doi.org/10.1111/1540-4560.00272.

Nadler, A. (2015). The other side of helping: Seeking and receiving help. In D. Schroeder \& W. Graziano (Eds.), The Oxford handbook of prosocial behavior. New York: Oxford University Press.

Nadler, A., \& Chernyak-Hai, L. (2014). Helping them stay where they are: Status effects on dependency/autonomy-oriented helping. Journal of Personality and Social Psychology, 106, 58-72.

Overall, N. C., Girme, Y. U., \& Simpson, J. A. (2016). The power of diagnostic situations: How support and conflict can foster growth and security. In C. R. Knee \& H. T. Reis (Eds.), Positive Approaches to Optimal Development. New York: Cambridge University Press.

Pelletier, L. G., Fortier, M. S., Vallerand, R. J., \& Briere, N. M. (2001). Associations among perceived autonomy support, forms of selfregulation, and persitence: A prospective study. Motivation and emotion, 25, 279-306.

Piferi, R. L., \& Lawler, K. A. (2006). Social support and ambulatory blood pressure: An examination of both receiving and giving. International Journal of Psychophysiology, 62, 328-336.

Powers, T. A., Koestner, R., \& Gorin, A. A. (2008). Autonomy support from family and friends and weight loss in college women. Families, Systems, \& Health, 26, 404-416.
Reeve, J. (2009). Why teachers adopt a controlling motivating-style toward students and how they can become more autonomy supportive. Educational Psychologist, 44, 159-178.

Rusbult, C. E., Kumashiro, M., Stocker, S. L., Kirchner, J. L., Finkel, E. J., \& Coolsen, M. K. (2005). Self processes in interdependent relationships: Partner affirmation and the Michelangelo phenomenon. Interaction Studies, 6, 375-391.

Ryan, R. M., \& Deci, E. L. (2000). Self-determination theory and the facilitation of intrinsic motivation, social development, and wellbeing. American Psychologist, 55, 68-78.

Ryan, R. M., \& Deci, E. L. (2017). Self-determination theory. Basic psychological needs in motivation, development, and wellness. New York, NY: Guildford Press.

Solstad, B. E., van Hoye, A., \& Ommundsen, Y. (2015). Social-contextual and interpersonal antecedents of coaches' basic need satisfaction: The intervening variable effect of providing autonomy-supportive coaching. Psychology of Sport and Exercise, 20, 84-93.

Uchino, B. N., Cacioppo, J. T., \& Kiecolt-Glaser, J. K. (1996). The relationship between social support and physiological processes: A review with emphasis on underlying mechanisms and implications for health. Psychological Bulletin, 119, 488-531.

Publisher's Note Springer Nature remains neutral with regard to jurisdictional claims in published maps and institutional affiliations. 